\title{
La explicación del riesgo de sequía en la Geografía escolar: una exploración desde los manuales escolares
} de Ciencias Sociales (Educación Primaria)

The risk of drought explanation in the school Geography: an exploration from the Social Sciences school textbooks (Primary Education)

\author{
Álvaro Francisco Morote Seguido \\ alvaro.morote@uv.es \\ Departamento de Didáctica de las Ciencias Experimentales y Sociales \\ Universitat de València (España)
}

\section{Resumen}

En la región mediterránea uno de los principales riesgos naturales son las sequías. Este fenómeno se ha agravado en las últimas décadas debido al incremento de la vulnerabilidad asociadas a actividades humanas y, según los escenarios futuros de cambio climático, se prevé que aumente la peligrosidad (mayor intensidad y frecuencia de los periodos secos). El objetivo de este trabajo es llevar a cabo un análisis de cómo se explica el riesgo de sequía en los manuales escolares de Ciencias Sociales ( $3^{\mathrm{er}}$ ciclo de Educación Primaria) en la Comunidad Valenciana (España). A partir de la consulta de estos recursos (las 5 editoriales más utilizadas), los resultados obtenidos indican que esta temática adquiere una escasa atención, sin definir el concepto de sequía y siendo una de las principales causas actuales a este fenómeno el cambio climático. Y respecto a las imágenes, estas se caracterizan por presentar una imagen catastrófica 
y descontextualizada con los contenidos. Por lo tanto, estos fenómenos tan característicos del clima mediterráneo se explican de una forma vulgar y donde el ser humano (factor vulnerabilidad) no tiene un protagonismo en la incidencia del riesgo.

Palabras clave: sequía; libros de texto; Ciencias Sociales; Educación Primaria.

\begin{abstract}
In the Mediterranean region one of the main natural risks are droughts. This phenomenon has worsened in the last decades due to the increase of the vulnerability (human activities). Furthermore, it is expected that danger will increase according to the forecast of future climate change scenarios (greater intensity and frequency of dry periods). The objective of this research is to carry out an analysis of the contents on the risk of drought proposed by the main textbooks of Social Sciences (3rd cycle of Primary Education) in the Valencian Community (Spain). With the analysis of these resources (the 5 most used editorials), the results obtained indicate that this topic receives little attention, without defining the concept of drought and climate change being one of the main causes of this phenomenon. In relation with the images, these are characterized by presenting a catastrophic and decontextualized image with the contents. Therefore, it would be a vulgar explanation of these phenomena (so characteristic of the Mediterranean climate) and where the human factor (vulnerability) and its incidence on risk would go unnoticed.
\end{abstract}

Key words: drought; textbooks; Social Sciences; Primary Education.

\title{
1 Introducción
}

En el área mediterránea, junto a las inundaciones, la sequía es uno de los principales riesgos que afecta a esta región (Olcina, 2020; Paneque, La Fuente \& Vargas, 2018). Este riesgo ha aumentado en las últimas décadas por el incremento de la vulnerabilidad (exposición del ser humano) y, además, se pronostica que el factor peligrosidad (frecuencia e intensidad de los periodos secos) aumente según los escenarios de cambio climático (Intergovernmental Panel on Climate Change, IPCC, 2018). Por ello, en España, la formación del profesorado sobre esta problemática actual y tratar estos temas en las aulas escolares debe ser una prioridad tal y como establece el actual currículo de Educación Primaria (área de Ciencias Sociales) (Real Decreto 126/2014, de 28 de febrero). Y en relación con el cambio climático, de cumplirse las previsiones existe la necesidad de conseguir una sociedad mejor formada, adaptada y 
concienciada a estos fenómenos donde la formación escolar debe ser un pilar fundamental (Morote, 2019a).

Diferentes autores (Chitsaz \& Hosseini, 2017; Paneque et al., 2018) han puesto de manifiesto que la sequía es uno de los riesgos ambientales más relevantes que afectan a algunas áreas del mundo y una de las mayores amenazas para la sociedad actual. En Europa, uno de los episodios más severos fue el de 2003, en el que un tercio del territorio y más de 100 millones de personas sufrieron este fenómeno (COPA COGECA, 2003). En cuanto a España, por su propia ubicación geográfica, la sequía constituye uno de los riesgos naturales de origen atmosférico más importantes (Olcina, 2018). Por ejemplo, uno de los episodios más graves en las últimas décadas fue el del primer lustro de los años noventa en el que su fase final (año 1995), 12 millones de habitantes (más del $25 \%$ de la población) sufrió restricciones de abastecimiento de agua (Morales, Olcina \& Rico, 2000).

Para analizar cualquier riesgo natural, en primer lugar, cabe tener en cuenta la componente humana ya que sin ser humano no hay riesgo (White, 1974). En cuanto a las diferentes definiciones sobre la sequía, Wilhite (2000) indica que es un fenómeno natural que se explica como una anomalía transitoria con valores de precipitación inferior a lo normal en una determinada región durante un periodo de tiempo más o menos prolongado. Olcina (2001) indica que se trata de un fenómeno recurrente de evolución lenta y progresiva, y que también sus efectos se acrecientan si se suceden en regiones donde las demandas de agua son superiores a la oferta disponible. Este autor también añade que este riesgo supone un desajuste en el ritmo anual de los valores de precipitación, de tal manera que las lluvias que se acumulan en territorios durante las épocas húmedas del año se reducen de forma notable consolidándose un déficit hídrico pluviométrico que se traduce, a su vez, en una reducción de agua para el abastecimiento.

Según La Calle (2007) este fenómeno es una situación de escasez motivada por una disminución de la cantidad de lluvia de duración e intensidad inusual ("sequía pluviométrica"), hecho que no debe confundirse con los conceptos de aridez o escasez habitual y natural de determinadas áreas o la carencia motivada por la explotación humana de recursos hídricos ("sequía hidrológica"). Esta última explicación es clave ya que normalmente se suele confundir aridez o escasez de agua con sequía, y además se suele asociar este fenómeno con territorios donde las precipitaciones son reducidas. Para llevar a cabo una explicación correcta cabe tener en cuenta que: 1) puede haber territorios semiáridos, pero sin escasez de agua. Ello dependerá de las 
características del abastecimiento de agua (oferta y demanda); y 2) territorios de climas húmedos afectados por la sequía debido al incremento de las demandas y/o mal uso y despilfarro del recurso coincidiendo con episodios de escasez de lluvia (Morote, 2019b). En este sentido, a finales de los noventa, Silverio (1998) ya indicó que en España la sequía no era una característica inusual de la fachada atlántica. E incluso autores como Olcina (2001) han denominado a este fenómeno como la "sequía cantábrica", caracterizada por ser más esporádica y de menor duración que las que afectan al sur y sureste peninsular español.

Respecto a la educación, esta es una de las variables no estructurales más importantes a tener en cuenta para hacer frente al cambio climático (United Nations, 2015). No obstante, tradicionalmente este factor ha sido ignorado a la hora de contemplar el riesgo (Morote \& Olcina, 2020). Por este motivo, Martínez y Olcina (2019) indican que tratar el cambio climático en las aulas escolares y la formación del profesorado debe ser una prioridad tal y como establece el actual currículo de Educación Primaria (objeto de estudio). Además, es de vital importancia tener en cuenta los conceptos de educación ambiental, ciudadana y geográfica y de vulnerabilidad espacial, todos ellos aspectos claves de la Didáctica de la Geografía ya que permiten conseguir una mayor comprensión e interpretación de un área geográfica (López y Oller, 2019; Tonda \& Sebastiá, 2003). En este sentido, Souto (2007) pone de manifiesto que formar a los futuros ciudadanos en temas vinculados con la ciencia en los países desarrollados es prioritario, y que la mejora de la labor y formación del profesorado sea quizá la mejor herramienta para aumentar su conocimiento, tanto en la vida cotidiana como en el ámbito científico, ya que es parte esencial de la educación geográfica para la ciudadanía.

En relación con los manuales escolares, estos aportan una aproximación de lo que puede enseñarse en las aulas (Prats, 2012; Valls, 2007). Respecto a la Educación Primaria, a pesar de que el uso de estos recursos ha disminuido en los últimos años (Morote \& Olcina, 2020), en la enseñanza de las Ciencias Sociales constituye la principal herramienta didáctica (cuando no la única) (Bel \& Colomer, 2018). Por su parte, Martínez y Olcina (2019) explican que actualmente los manuales escolares son el recurso didáctico más usado por los docentes para la enseñanza de la Climatología. En España, el análisis de los libros de texto desde la Didáctica de las Ciencias Sociales es una línea de investigación clásica (Pagès, 2008). No obstante, en cuanto al número de contribuciones en relación con la Geografía, esta no es una temática de trabajo que destaque sobre el resto de las líneas de investigación en Didáctica de la Geografía. Hecho que, en cambio, si sucede en Historia (Souto, 2002). Como explicaban García, Pardo y Rebollo (2009) hace una década, el número de trabajos relacionados con los manuales de Geografía y 
problemas ambientales era escaso y no había una metodología específica para analizar sus contenidos. Y hoy en día esta tendencia no se ha resuelto (Morote \& Olcina, 2020). Esta escasa producción aún se agrava más para el caso de los estudios que se vinculan con los riesgos naturales en la Educación Primaria y concretamente con el tema aquí analizado (el riesgo de sequía). Recientemente, en vinculación con los aspectos climáticos destacan algunas contribuciones que han analizado los libros de texto (Arrebola \& Martínez, 2017; Cuello \& García, 2019; Martínez \& López, 2016; Morote, 2020; Morote \& Olcina, 2020; Olcina, 2017; Ramos \& Calonge, 2014; Serantes, 2015). Respecto a la sequía, tanto en el ámbito internacional como nacional, los trabajos son escasos, destacando el trabajo de García et al. (2009) que, a parte del análisis de la sequía, se estudian otros relacionados con la crisis ambiental actual (problemas ambientales, cambio climático, pérdida de biodiversidad, desertificación) en los manuales de Geografía de la ESO (Comunidad de Madrid).

El interés de este trabajo se debe a diferentes motivos: 1) la problemática actual que conlleva el cambio climático y sus efectos (actuales y futuros) en la sociedad debido a la mayor frecuencia e intensidad de episodios atmosféricos extremos (caso de las sequías) (IPCC, 2018). Esto se agrava aún más en el área de estudio por ser una "región-riesgo" (Calvo, 2001), principalmente debido a las actividades humanas implementadas (incremento de la demanda de agua en las últimas décadas); 2) la importancia de tratar las sequías en la Educación Primaria como establece el actual currículo tanto a nivel nacional (Real Decreto 126/2014, de 28 de febrero) como a nivel autonómico valenciano (Decreto 108/2014, de 4 de julio); 3) el interés por analizar cómo se explica esta temática en los libros de texto utilizados en este nivel educativo. Ello cobra una mayor relevancia debido a los escasos trabajos previos sobre la sequía desde la Didáctica de la Geografía (Ciencias Sociales), tanto a nivel nacional e internacional. Además, no cabe olvidar el interés que adquiere conocer esta cuestión ya que van dirigidos a las cohortes más jóvenes de la sociedad y porque serán ellos quienes concienciarán y enseñaran a las generaciones futuras; 4) la influencia de los libros de texto en la construcción de una opinión pública sobre un asunto determinado; y 5) la preocupación existente debido a que los libros de texto siguen siendo el principal material utilizado en las aulas de Educación Primaria y continúan teniendo una visión enciclopédica, informativa y con una escasa visión crítica e interpretativa del territorio (actividades meramente reproductivas) (Sáiz, 2011).

El objetivo de este trabajo es llevar a cabo un análisis de cómo se explica el riesgo de sequía en los manuales escolares de Ciencias Sociales ( $3^{\text {er }}$ ciclo de Educación Primaria; cursos $5^{\circ}$ y $6^{\circ}$ ) de las principales editoriales que se utilizan en la Comunidad Valenciana (España). Concretamente 
se prestará atención a las definiciones, las causas y consecuencias, los factores que intervienen (climáticos y humanos), soluciones que se proponen y un análisis exploratorio de las imágenes que se insertan. En cuanto a las hipótesis de partida se establece que la sequía adquiere una escasa atención y confusa en los libros de texto. Por otra parte, uno de los principales efectos de estos eventos estaría relacionado con el cambio climático y, en cuanto a las imágenes, estas presentarían un excesivo catastrofismo. Por lo tanto, estos fenómenos tan característicos del clima mediterráneo se explicarían de una forma vulgar y donde el ser humano (factor vulnerabilidad) no tendría un protagonismo en la incidencia del riesgo.

\section{Fuentes y metodología}

Los contenidos que deben recoger los manuales escolares tienen que tener en cuenta la normativa ya que esta es la que rige sobre los contenidos, estándares de aprendizaje y criterios de evaluación. En la actualidad, en España, en relación con el currículo de Educación Primaria, es el Estado quien establece las enseñanzas mínimas mediante el Real Decreto 126/2014 de 28 de febrero. Sin embargo, los contenidos docentes están transferidos a las comunidades autónomas que se encargan de concretarlos en un currículo propio. Para el caso de estudio aquí analizado, la Comunidad Valenciana, el currículo de Educación Primaria se rige mediante el Decreto 108/2014 de 4 de julio. Y respecto a los contenidos vinculados con el riesgo de sequía, estos se insertan en la asignatura de Ciencias Sociales, en el Bloque 2 "El mundo en el que vivimos".

De manera general se trata de una temática que debe tratarse en todos los cursos, aunque no siempre se recoge de forma literal. Por ejemplo, para el $3^{\text {er }}$ ciclo (objeto de estudio), en $5^{\circ}$, algunos de los contenidos donde debería insertarse el tema de la sequía son: "paisaje mediterráneo, oceánico, de montaña y subtropical. Clima y actividades humanas: agricultura y turismo", "nociones de vertiente hidrográfica y régimen fluvial y su relación con el clima. Infraestructuras hidráulicas: embalses, presas y azudes" y "elementos del medio físico: suelo, relieve, clima (temperatura, precipitación e insolación) e hidrografía". Respecto a los criterios de evaluación cabe destacar "examinar algunos problemas ambientales relacionados con el desarrollo sostenible como el agotamiento, escasez o deterioro por contaminación de los recursos que se pueden obtener del suelo y el subsuelo especialmente las materias primas y el agua como resultado de las actividades humanas". En cuanto al $6^{\circ}$ curso se pueden mencionar los siguientes contenidos: "distribución de climas: ecuatorial, tropical, mediterráneo, oceánico, continental, subtropical (Canarias), polar y de montaña", "identificación de los elementos que se 
representan en un climograma e interpretación de sus características. Interacción clima y actividades humanas" y "noción de caudal y su relación con el clima". En vinculación con los criterios de evaluación $\left(6^{\circ}\right)$ que puedan tener una relación con la sequía destacan "analizar algunas de las manifestaciones del cambio climático como una consecuencia de la interacción de la actividad humana con el medio sugiriendo algunas posibles actuaciones para frenar dicho cambio".

Para esta investigación se han analizado los libros de texto de Ciencias Sociales $\left(3^{\text {er }}\right.$ ciclo de Educación Primaria; cursos $5^{\circ}$ y $6^{\circ}$ ) de las principales editoriales que se utilizan en la Comunidad Valenciana (España) y que coinciden con la mayoría de las editoriales usadas en el conjunto del territorio español (Tabla 1). En primer lugar, para la justificación de la elección de este ciclo se debe a que coincide con el periodo cognitivo más complejo de la Educación Primaria (11-12 años) y porque es el previo a la Educación Secundaria Obligatoria (ESO). De esta manera se puede llevar a cabo un análisis más exhaustivo de la complejidad de los contenidos propuestos.

En segundo lugar, en cuanto al marco geográfico (Com. Valenciana) la justificación de su elección se debe a varios motivos: 1) existen investigaciones previas sobre el análisis de libros de texto de Ciencias Sociales que han justificado el uso de las principales editoriales utilizadas en esta región (Anaya, Santillana, SM, Vicens Vives y Bromera) a partir de la consulta con el profesorado en servicio, tanto para la revisión de contenidos de Historia (Bel y Colomer, 2018; Sáiz, 2011) como de contenidos geográficos como Climatología (Morote, 2020) y cambio climático (Morote \& Olcina, 2020); y 2) la región valenciana es una de las áreas del mediterráneo más vulnerables a los efectos del cambio climático (IPCC, 2018).

En tercer lugar, respecto a los libros de texto consultados se han examinado los manuales más actuales (un total de 10; 5 por curso) publicados tras la aprobación de la LOMCE (Ley Orgánica 8/2013, de 9 de diciembre, para la Mejora de la Calidad Educativa). Cabe insistir que tanto el número de libros de texto como las editoriales objeto de estudio (Anaya, Bromera, Santillana, SM y Vicens Vives) son representativas como ponen de manifiesto trabajos previos realizados en otros ámbitos como, por ejemplo, el de García et al. (2009) para el caso de la ESO en la Comunidad de Madrid (Ciencias Sociales, Geografía e Historia) o la Tesis Doctoral de SánchezFuster (2017) en la Región de Murcia (Educación Primaria). Respecto a esta última, las editoriales y libros analizados (un total de 5) han sido seleccionadas a partir de los resultados de una encuesta realizada a docentes en activo (ver Sánchez-Fuster, 2017, p. 149). 
Tabla 1. Manuales escolares de Ciencias Sociales analizados

( $3^{\text {er }}$ ciclo de Educación Primaria)

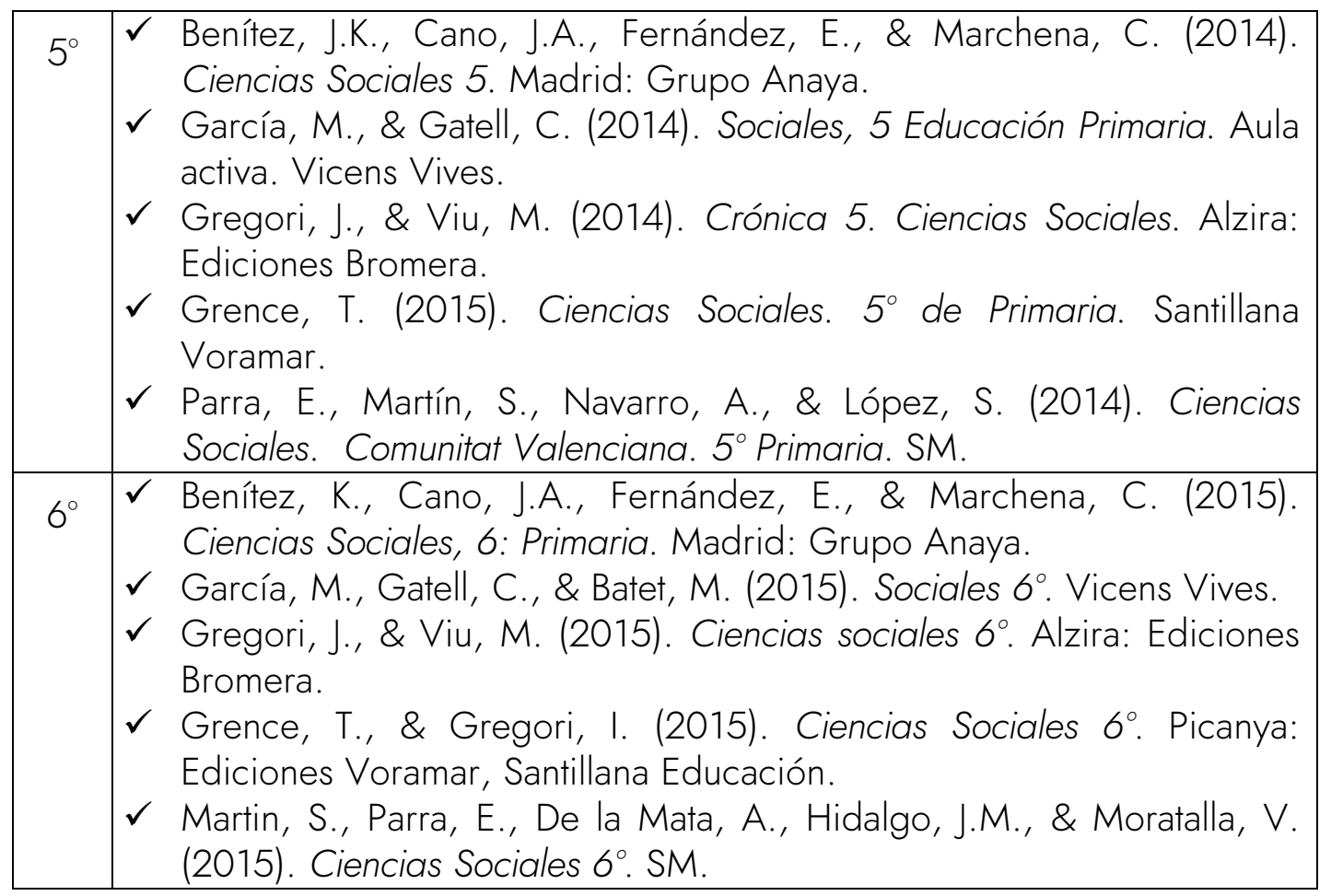

Fuente: elaboración propia

Para llevar a cabo los objetivos propuestos se ha realizado una revisión de los contenidos que incorporan los libros de texto sobre la sequía y si se adecuan o no al currículo expuesto anteriormente teniendo en cuenta: 1) análisis de la definición completa del riesgo de sequía (peligrosidad y vulnerabilidad); 2) causas, consecuencias y soluciones para mitigar estos fenómenos; y 3) análisis de las imágenes (ilustraciones, fotografías, mapas, etc.), para comprobar si están contextualizadas con los contenidos que se explican.

\section{Resultados}

\subsection{El riesgo de sequía. Definiciones y términos erróneamente asociados}

Los contenidos sobre el riesgo de sequía en los libros de texto de Ciencias Sociales de Educación Primaria se insertan en las unidades didácticas relacionadas con el tiempo atmosférico y el clima. Sin embargo, debido a que estos contenidos son transversales (temas de hidrografía, paisaje, vegetación, etc.), también se suelen ubicar en otras partes del temario. Esto sucede especialmente en $6^{\circ}$, ya que en $5^{\circ}$ se insertan unidades didácticas exclusivamente sobre Climatología (ver Tabla 2). Este hecho repercute en que los contenidos sobre la sequía en el último curso de Educación Primaria sean más reducidos. También cabe destacar que la mayoría 
de la denominación de los títulos de este temario coincide con los geo-factores de la descripción regional y no con un análisis de problemas territoriales o socio-ambientales. Esta primera observación denota una reducida problematización de los contenidos que se pueden encontrar como se destacará más adelante.

Tabla 2. Denominación de las unidades didácticas de los libros de texto de Ciencias Sociales ( $3^{\text {er }}$ ciclo de Educación Primaria) donde se insertan contenidos sobre la sequía

\begin{tabular}{|c|c|}
\hline \multicolumn{2}{|r|}{$5^{\circ}$ DE EDUCACIÓN PRIMARIA } \\
\hline EDITORIAL & TITULO DE LA UNIDAD DIDÁCTICA \\
\hline Anaya & $\begin{array}{l}\text { Tema 4. El clima } \\
\text { Tema 5. Los climas y la hidrografía de España }\end{array}$ \\
\hline Bromera & $\begin{array}{l}\text { Tema 2. Clima y Paisaje } \\
\text { Tema 4. El clima y los ríos de la Comunidad } \\
\text { Valenciana }\end{array}$ \\
\hline Santillana & $\begin{array}{l}\text { Tema 3. Las aguas de España } \\
\text { Tema 4. La atmósfera y el clima }\end{array}$ \\
\hline SM & Tema 2. El clima \\
\hline Vicens Vives & Tema 3. El clima y la vegetación \\
\hline \multicolumn{2}{|r|}{$6^{\circ}$ DE EDUCACIÓN PRIMARIA } \\
\hline EDITORIAL & TITULO DE LA UNIDAD DIDÁCTICA \\
\hline Anaya & $\begin{array}{l}\text { Tema 2. La hidrografía y el clima } \\
\text { Tema 3. Los problemas medioambientales }\end{array}$ \\
\hline Bromera & Tema 2. El clima y la vegetación \\
\hline Santillana & $\begin{array}{l}\text { Tema 2. Las aguas y los climas de Europa y de } \\
\text { España } \\
\text { Tema 5. El impacto humano en el medio ambiente }\end{array}$ \\
\hline SM & $\begin{array}{l}\text { Tema 1. Los paisajes de España } \\
\text { Tema 2. Los paisajes de Europa }\end{array}$ \\
\hline Vicens Vives & $\begin{array}{l}\text { Tema 1. El medio físico de Europa } \\
\text { Tema 2. El medio físico de España }\end{array}$ \\
\hline
\end{tabular}

Fuente: elaboración propia

Respecto a la definición del riesgo de sequía cabe indicar que tan sólo 2 de 10 manuales llevan a cabo una explicación de este fenómeno (Tabla 3). Por ejemplo, una de las definiciones más acertadas y correctas que se han analizado es la que realiza el manual de $5^{\circ}$ de Educación Primaria de la editorial Anaya en la que se hace referencia a la disminución de lluvias durante un periodo normal (valores medios) y que en España se suele dar en la zona mediterránea (Tabla 3). No obstante, respecto a esta definición cabría corregir y/o matizar el término de "escasez de agua" ya que este se relaciona con la demanda de agua (factor humano). También cabe poner de manifiesto que la clave de todo este argumento es saber si los/as alumnos/as 
de 11-12 años entienden qué es un período normal, incluso si esto mismo lo entienden los propios profesores. Una segunda definición correcta es la que añade la editorial Bromera en el manual de $5^{\circ}$ en la que se explica que "la sequía se registra, por ejemplo, en el extremo sur del territorio valenciano. La falta de lluvias origina sequías, que son muy perjudiciales para la agricultura y el incremento del riesgo de incendios forestales" (Gregori \& Viu, 2014, p. 30).

Sin embargo, también se encuentran definiciones $y / o$ explicaciones que no son del todo precisas y en la mayoría de los libros de texto se confunden términos e incluso no se incorpora ninguna información sobre este fenómeno (ver Tabla 3). Por ejemplo, suele insertarse información de la sequía que se asocia a veranos secos como recoge el manual de $5^{\circ}$ (Anaya). Esta explicación no es correcta ya que si por algo caracteriza al clima mediterráneo es por presentar una estación seca durante los meses estivales, la denominada sequía estival. Pero esto es algo estructural, es decir, un rasgo característico de la región mediterránea, incluso de la región atlántica española (Olcina, 2001). Y a ello, cabe sumar que es durante este periodo cuando se intensifica la demanda de agua para usos urbano-turísticos, regadío, etc., agravando la escasez de agua.

Por tanto, sería necesario incorporar una definición que diferenciara si la sequía se debe a un factor natural (sequía pluviométrica) o al nivel de la demanda inducida por el ser humano y la disponibilidad de recursos hídricos (sequía hidrológica). Esta última diferenciación tampoco se ha encontrado en ninguno de los manuales consultados. Aunque es una explicación compleja para un alumnado con una edad de 11-12 años, habría que hacer el esfuerzo por comenzar a explicar estos conceptos de una forma sencilla. Respecto a la definición del riesgo de sequía debería seguirse una explicación fácil según se indica en el apartado introductorio o según las explicaciones insertadas en las editoriales de Anaya y Bromera para el $5^{\circ}$ curso, a saber: una aclaración que ponga de manifiesto que este fenómeno se trata de una reducción coyuntural del volumen de precipitaciones por debajo de los valores normales durante un tiempo prolongado. E insistir que esa disminución de precipitaciones puede inducir o no a problemas de abastecimiento. Esto último dependerá de las características de la gestión del suministro de agua, del volumen de la demanda, la disponibilidad de recursos hídricos convencionales y no convencionales, etc. 


\section{Tabla 3. Definiciones sobre la sequía según los libros de texto de Ciencias Sociales ( $3^{\text {er }}$ ciclo de Educación Primaria)}

\section{Anaya $5^{\circ}$}

$\checkmark$ Se encuentra información cuando se explica el clima mediterráneo (Tema 4): "Precipitaciones muy escasas e irregulares. Los veranos son muy secos, llegándose a producir períodos de fuerte sequía" (Benítez, Cano, Fernández y Marchena, 2014, p. 58).

$\checkmark$ También en el apartado de "Riesgos climáticos" se explica que "una sequía es la falta o escasez de agua que tiene un territorio cuando no se han producido lluvias normales. En nuestro país se dan, sobre todo, en la zona mediterránea. Las sequías comienzan cuando se retrasa el inicio de la estación de lluvias y una disminución en la intensidad de estas. En algunos casos, este retraso puede afectar no solo a una estación de lluvia, sino a varias" (Benítez et al., 2014, p. 62) (Tema 4).

$\checkmark$ En el Tema 5 se relaciona sequía con la España seca: "las precipitaciones son escasas e irregulares, produciéndose sobre todo en primavera y otoño. En verano apenas caen. A estas zonas se les denomina la España seca, aunque a veces se producen aguaceros y lluvias torrenciales, que duran solo unas horas y que provocan grandes inundaciones" (Benítez et al., 2014, p. 68).

\section{Anaya $6^{\circ}$}

No hay definición.

\section{Bromera $5^{\circ}$}

$\checkmark$ En el Tema 2 en el apartado de "Riesgos naturales climáticos" se inserta un texto sobre los riesgos derivados del clima. En él se explica que "la sequía se registra, por ejemplo, en el extremo sur del territorio valenciano. La falta de lluvias origina sequías, que son muy perjudiciales para la agricultura y el incremento del riesgo de incendios forestales" (Gregori y Viu, 2014, p. 30).

\section{Bromera $6^{\circ}$}

$\checkmark$ No hay definición.

\section{Santillana $5^{\circ}$}

No hay definición.

\section{Santillana $6^{\circ}$}

$\checkmark$ No hay definición.

\section{SM $5^{\circ}$}

$\checkmark$ Aunque no se encuentra ninguna definición se explica que "las sequías hacen desaparecer la vegetación y los animales emigran a otros lugares con agua" (Parra, Martin, Navarro y López, 2014, p. 45) y además siendo el cambio climático la causa de este fenómeno (Parra et al., 2014). 


\section{$S M 6^{\circ}$}

$\checkmark$ No se encuentra ninguna definición, pero en un apartado titulado "iSOS!" se explica que las sequías, junto a otros riesgos como las inundaciones y los incendios "son de origen natural" (Martin, Parra, De la Mata, Hidalgo y Moratalla, 2015, p. 30).

\section{Vicens Vives $5^{\circ}$}

$\checkmark$ No se encuentra ninguna definición, pero en un apartado dedicado a la vegetación mediterránea se explica que este tipo de vegetación "está adaptada al calor y a la sequía" como los "bosques de hoja perenne (pinos, encinas y alcornoques), sotobosque seco (carrascas, brezo y plantas aromáticas), maquia o garriga (formación vegetal de arbustos y hierbas), estepa (hierbas y arbustos espinosos que crecen en zonas áridas)" (García y Gatell, 2014, p. 51).

\section{Vicens Vives $6^{\circ}$}

$\checkmark$ No se encuentra ninguna definición sobre la sequía, pero en un apartado dedicado al clima continental se explica que "la vegetación está adaptada a la sequía y a los inviernos fríos y a los veranos muy cálidos" (García, Gatell y Batet, 2015, p. 32).

$\checkmark$ Respecto a la vegetación se señala que en la Meseta "la vegetación reúne especies adaptadas al calor y la sequía de verano" (García et al., 2015, p. 38).

$\checkmark$ También cuando se explica el clima de las Islas Canarias se recoge que "en general, en la ladera sur de las montañas se encuentran plantas xerófilas adaptadas a la sequía, como el cardón y la palmera" (García et al., 2015, p. 39).

Fuente: elaboración propia

En relación con los territorios afectados por el riesgo de sequía se han analizado las regiones españolas que tienen riesgo de sufrir este fenómeno. La mayoría, 7 de los 10 libros de texto consultados, explican que este fenómeno se registra en la región mediterránea y especialmente en el sur del territorio valenciano (Tabla 4). No obstante, a la hora de localizar geográficamente este fenómeno se utilizan términos poco adecuados. Por ejemplo, el libro de $5^{\circ}$ de Educación Primaria (Santillana) lo relaciona con la sequía estival y con el estiaje. Otros como el manual de Anaya $\left(5^{\circ}\right)$ vincula las regiones que se ven afectadas por este fenómeno en la Península lbérica como "la España seca" (Benítez et al., 2014, p. 68). De nuevo, esto es un error ya que en todo caso debería asociarse a las regiones de clima semiárido, pero esto no tiene por qué significar que haya sequía. También hay editoriales que asocian la ubicación de la afección de este riesgo a la hora de tratar la vegetación y el paisaje. Es el caso de la editorial Vicens Vives $\left(5^{\circ}\right.$ y $\left.6^{\circ}\right)$ pero siguen confundiendo la sequía con la reducción de precipitaciones estructural del clima mediterráneo (sequía estival o estiaje). Respecto a los libros de texto que incorporan otras regiones diferentes a la mediterránea cabe destacar el manual de $6^{\circ}$ de Vicens Vives que hace referencia al interior de la península (clima continental; aunque también mediterráneo) y a las 
Islas Canarias. No obstante, en ningún manual se cita que también hay climas húmedos, como el que caracteriza a la fachada atlántica norte y cantábrica española donde los episodios de sequía tan poco son nada inusuales.

Tabla 4. Explicación sobre la localización de los territorios afectados por el riesgo de sequía en España según los libros de texto de Ciencias Sociales ( $3^{\mathrm{er}}$ ciclo de Educación Primaria)

\begin{tabular}{|c|c|c|}
\hline EDITORIAL & $\begin{array}{c}\text { ¿SE EXPLICA QUE LA SEQUÍA ES UN RASGO } \\
\text { CARACTERÍSTICO DEL CLIMA DEL } \\
\text { MEDITERRÁNEO? }\end{array}$ & $\begin{array}{c}\text { ¿SE EXPLICA QUE } \\
\text { LA SEQUIIA } \\
\text { TAMBIÉN SE } \\
\text { PUEDE REGISTRAR } \\
\text { EN OTRAS ÁREAS } \\
\text { DE ESPAÑA? }\end{array}$ \\
\hline Anaya $5^{\circ}$ & $\begin{array}{l}\text { Sí: "En nuestro país se dan sobre todo en la zona } \\
\text { mediterránea" (Benítez et al., 2014, p. 63). Se vincula } \\
\text { a la parte mediterránea de la Península Ibérica con "la } \\
\text { España seca" (Benítez et al., 2014, p. 68). }\end{array}$ & No. \\
\hline Anaya $6^{\circ}$ & No hay información. & No. \\
\hline Bromera $5^{\circ}$ & $\begin{array}{l}\text { Sí: aunque se cita sólo que se da, por ejemplo, en el } \\
\text { sur valenciano (Gregori y Viu, 2014, p. 30). }\end{array}$ & No. \\
\hline Bromera $6^{\circ}$ & $\begin{array}{l}\text { Sí: aunque realmente no se habla de la sequía sino de } \\
\text { "estiaje" (Gregori y Viu, 2015, p. 26). }\end{array}$ & No. \\
\hline Santillana $5^{\circ}$ & $\begin{array}{l}\text { Sí: aunque se cita cuando se habla de: 1) la sequía } \\
\text { estival ("precipitaciones son escasas e irregulares. No } \\
\text { sobrepasan los } 600 \mathrm{l} / \mathrm{m}^{2} \text { anuales. Se concentran en las } \\
\text { estaciones de primavera y otoño, mientras que en } \\
\text { verano suele haber sequía") (Grence, 2015, p. 62); y } \\
\text { 2) del estiaje ("los ríos que atraviesan la Comunidad } \\
\text { Valenciana son poco caudalosos, sobre todo en } \\
\text { verano. La escasez de lluvias en esta estación reduce su } \\
\text { caudal; por ello, tienen estiaje") (Grence, 2015, p. } \\
\text { 48). }\end{array}$ & No. \\
\hline Santillana $6^{\circ}$ & Sí: pero se confunde con la sequía estival. & No. \\
\hline SM $5^{\circ}$ & No hay información. & No. \\
\hline SM $6^{\circ}$ & Sí: fenómeno de origen natural. & No. \\
\hline $\begin{array}{l}\text { Vicens Vives } \\
5^{\circ}\end{array}$ & $\begin{array}{l}\text { Sí: cuando se habla en relación con la vegetación } \\
\text { mediterránea. }\end{array}$ & No. \\
\hline $\begin{array}{l}\text { Vicens Vives } \\
6^{\circ}\end{array}$ & $\begin{array}{l}\text { Sí: cuando se habla en relación con la vegetación } \\
\text { mediterránea. }\end{array}$ & $\begin{array}{l}\text { Sí: Islas Canarias, } \\
\text { interior de la } \\
\text { Península Ibérica } \\
\text { (clima continental). }\end{array}$ \\
\hline
\end{tabular}

Fuente: elaboración propia

Respecto a los términos erróneos que se asocian a la sequía caben destacar: sequía estival y estiaje, España seca, aridez, escasez de agua y desertificación. En cuanto a los primeros, por ejemplo, el libro de $5^{\circ}$ (Anaya) explica que "en verano son bastante frecuentes los periodos de 
sequía" (Benítez et al., 2014, p. 76), o Bromera (5), que en el Tema 4, en relación con el estiaje explica que "normalmente los ríos valencianos llevan menos agua en verano porque es cuando llueve menos. El periodo durante el cual el río lleva menos agua de la habitual se denomina estiaje" (Gregori y Viu, 2014, p. 60). Cabe indicar que en relación con esto último (reducción del caudal del río en verano) es algo característico de los cursos fluviales de la región mediterránea.

En relación con la "España seca" es la editorial Anaya (5 curso) la única que introduce este término. Se cita esta denominación en el Tema 5 cuando se vincula la sequía con la España seca y la sequía estival: "en verano son bastante frecuentes los periodos de sequía" (Benítez et al., 2014, p. 76). En cuanto a la "aridez", es también este mismo manual el único que lo cita, concretamente en la actividad "define los siguientes términos: meteorología, climograma, amplitud térmica y aridez" (Benítez et al., 2014, p. 61). Sin embargo, cabe indicar que en el texto no se explica la definición de este término, por tanto, se entiende que el alumnado debe buscar estas definiciones en algún diccionario, internet, etc., o incluso a partir de la explicación del profesor/a. La "escasez de agua" es otro término controvertido y que normalmente se asocia a sequía. No obstante, un territorio que presenta escasez de agua no tiene por qué estar afectado por la sequía. Al respecto, la editorial Anaya, en $6^{\circ}$ relaciona este concepto a la hora de explicar la sequía y los recursos hídricos. Por ejemplo, se indica que los recursos hídricos son limitados, al igual que se habla del malgasto de agua (Benítez, Cano, Fernández y Marchena, 2015, p. 21). Esto tampoco es correcto vincularlo con la sequía, ya que la escasez de recursos hídricos dependerá de la oferta y demanda de agua ya que puede haber territorios con problemas de abastecimiento sin necesidad de estar en situación de sequía como sucede en algunos puntos del sureste peninsular español. 
Tabla 5. Definiciones correctas que se deberían contemplar en los manuales escolares sobre: sequía estival y estiaje, España seca, aridez, escasez de agua y desertificación

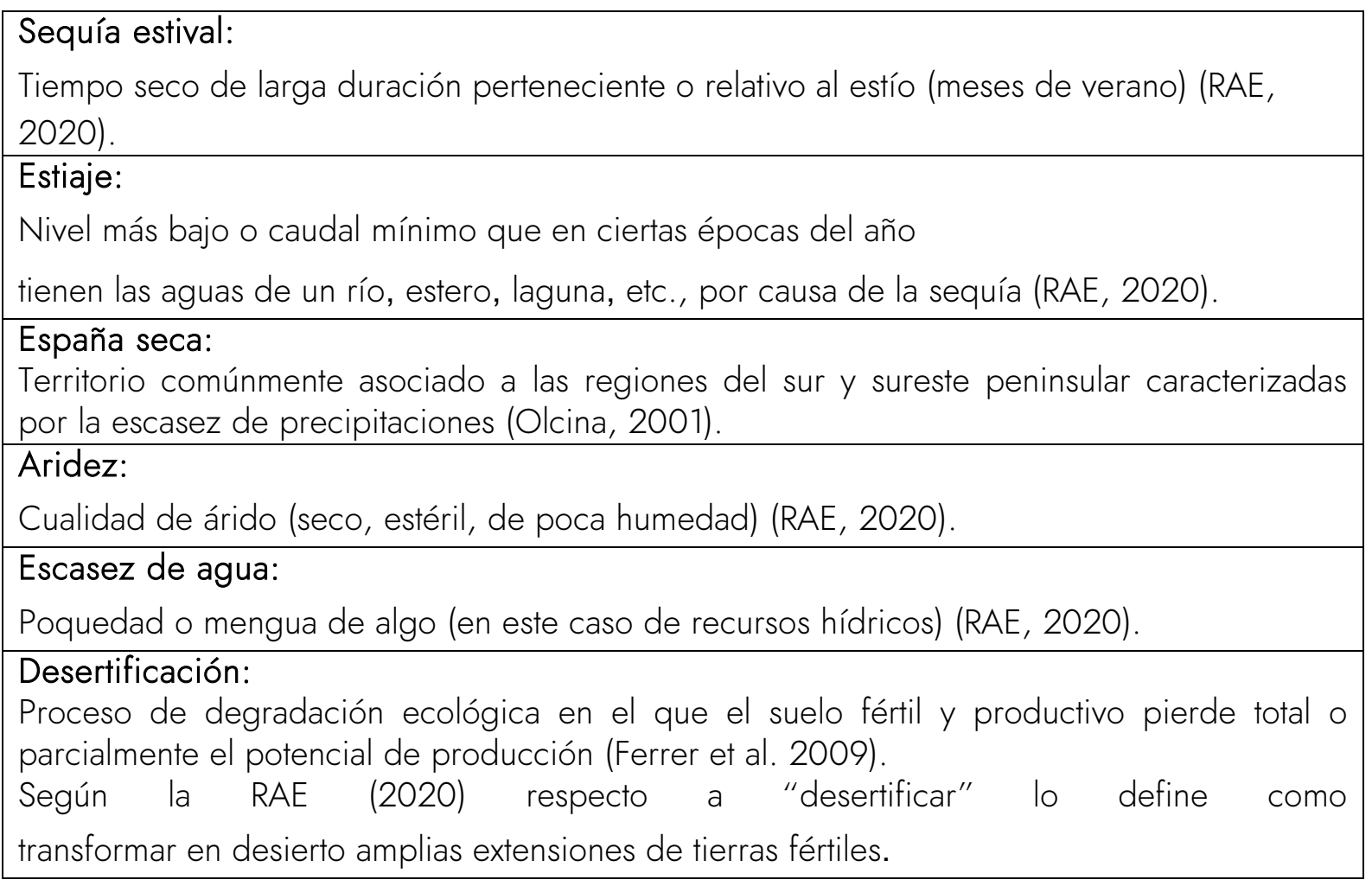

Fuente: elaboración propia

Finalmente se ha identificado el concepto de "desertificación". Según Ferrer et al. (2009) es un proceso de degradación ecológica en el que el suelo fértil y productivo pierde total o parcialmente el potencial de producción. Algunas de las causas son la destrucción de la cubierta vegetal (deforestación), la sobreexplotación de acuíferos, la erosión de los suelos, la sobreirrigación y la salinización de las tierras o la falta de agua. Según estos autores, el ser humano, con frecuencia favorece e incrementa este proceso como consecuencia de diferentes actividades (cultivo y el pastoreo excesivo o la deforestación) (ver Tabla 5). En este caso, este término, complejo, es introducido en los manuales de $5^{\circ}$ de Bromera y Vicens Vives. Para el caso del primero cabe indicar que se trata de una explicación correcta. En el Tema 2 en el apartado de "Riesgos naturales climáticos" se inserta un texto sobre los riesgos derivados del clima. En el se introduce una definición sobre la desertización, comúnmente asociada a la sequía: "la desertización es la transformación de una zona en un desierto. Si se produce por causa de las actividades humanas, como la sobreexplotación agrícola o el pastoreo, o incluso por incendios forestales provocados por las personas, se denomina desertificación. El sureste peninsular es la zona con más riesgo de desertización" (Gregori \& Viu, 2014, p. 30). Por su parte, en el manual de Vicens Vives se confunde la sequía y el descenso de las precipitaciones 
con el aumento del proceso de desertización: "el aumento de las temperaturas y el descenso de las precipitaciones puede provocar la desertización en algunas zonas del planeta. El sur de España, por ejemplo, comienza a tener problemas graves de desertización" (García \& Gatell, 2014 , p. 53). En ambos casos citan este problema en el sur y sureste peninsular, pero cabe matizar y explicar mejor la causa natural, por ejemplo, incidir en que los periodos de sequía pueden aumentar tanto en intensidad y frecuencia como recogen los informes intergubernamentales sobre cambio climático (IPCC, 2018).

\subsection{Factores que influyen en el riesgo de sequía, soluciones para mitigar sus efectos y análisis de las imágenes}

En relación con los factores que influyen en el riesgo de sequía según la información proporcionada por los libros de texto analizados, cabe indicar que la mayoría (9 de los 10 manuales) indican que una de las causas es el cambio climático (ver Tabla 6). Otras explicaciones más acertadas argumentan que los efectos de las sequías se agravarán en el futuro en intensidad y frecuencia debido a este fenómeno según recoge el manual de $5^{\circ}$ de Vicens Vives. Una tercera tipología de explicaciones es aquella en la que se indica que este riesgo es de origen natural, es decir, algo característico del clima mediterráneo según se destaca en el libro de $6^{\circ}$ de SM. Respecto al cambio climático también cabe poner de manifiesto que existen contradicciones entre una misma editorial. Por ejemplo, en el libro de $6^{\circ}$ de SM se explica que la sequía es un fenómeno de origen natural, en cambio, en el manual de $5^{\circ}$ se da a entender que la causa principal es el cambio climático por causa antrópica.

Respecto a la influencia del ser humano en el riesgo de sequía cabe destacar que la mayoría de las editoriales no han insertado ninguna información (7 de 10 manuales). De los restantes, 2 libros de texto (los manuales de $5^{\circ}$ y $6^{\circ}$ de Anaya) explican cómo el ser humano está afectando a la sequía debido al "malgasto de agua" y al "incremento del consumo de agua". Sin embargo, esta información se inserta en un apartado titulado "Nuestro clima está cambiando", pero se puede observar que esta acción poco tiene que ver con un cambio del clima. El manual restante ( $5^{\circ}$ curso de la editorial Bromera) incorpora una de las explicaciones más acertadas del conjunto del análisis de la investigación que aquí se presenta ya que se destaca una información muy positiva para poder entender la diferencia entre la sequía y la escasez de agua: "la sobreexplotación de acuíferos que no tiene nada que ver con la sequía ni la falta de lluvias" (Gregori \& Viu, 2014, p. 57). Esta argumentación es notablemente positiva para entender y saber interpretar que la sequía no es sinónimo de escasez de agua. 
Tabla 6. Factores que intervienen en la afectación de la sequía según los libros de texto de Ciencias Sociales ( $3^{\text {er }}$ ciclo de Educación Primaria)

\begin{tabular}{|c|c|c|}
\hline EDITORIALES & $\begin{array}{c}\text { SER } \\
\text { HUMANO }\end{array}$ & $\begin{array}{c}\text { CAMBIO } \\
\text { CLIMÁTICO }\end{array}$ \\
\hline $\begin{array}{l}\text { Anaya } 5^{\circ} \\
\text { - En el Tema 4, en el apartado titulado "Nuestro clima está } \\
\text { cambiando" se explica que se está "malgastando el agua" } \\
\text { (Benítez et al., 2014, p. 62). Pero esto realmente no tiene } \\
\text { nada que ver con un cambio del clima. También se menciona } \\
\text { que respecto a los consejos para reducir los gases } \\
\text { contaminantes se debería "ducharse en vez de bañarse, y } \\
\text { reciclar el agua de la ducha para otras actividades" (Benítez } \\
\text { et al., 2014, p. 62). } \\
\text { - En el Tema } 5 \text { se indica que "las temperaturas máximas } \\
\text { subirán entre } 5 \text { y } 8^{\circ} \mathrm{C} \text { y las lluvias disminuirán en España } \\
\text { hasta el año } 2100 \text { a causa del cambio climático, lo que } \\
\text { provocará diversos impactos en la agricultura, la salud y en } \\
\text { los recursos hídricos" (Benítez et al., 2014, p. 66). También } \\
\text { se inserta una actividad sobre los consejos que darían los } \\
\text { alumnos para ahorrar agua: "¿qué consejos darías para } \\
\text { ahorrar agua?" (Benítez et al., 2014, p. 79). }\end{array}$ & Sí. & Sí. \\
\hline $\begin{array}{l}\text { Anaya } 6^{\circ} \\
\text { - En cuanto a los factores humanos se explica que "España es } \\
\text { uno de los principales consumidores de agua" y que "uno } \\
\text { de los principales problemas es la sobreexplotación que } \\
\text { provocan las actividades humanas" (Benítez et al., 2015, p. } \\
\text { 26). } \\
\text { - Respecto al cambio climático se indica que "un factor } \\
\text { importante que incide en los recursos hídricos es el } \\
\text { calentamiento global, que deriva en la desaparición de } \\
\text { glaciares, depósitos de agua dulce y en temperaturas más } \\
\text { altas que favorecen las sequías" (Benítez et al., 2015, p. 26). } \\
\text { También se explica que una de las consecuencias del cambio } \\
\text { climático es "el incremento de las lluvias y los temporales y } \\
\text { grandes sequías" (Benítez et al., 2015, p. 34). }\end{array}$ & Sí. & Sí. \\
\hline $\begin{array}{l}\text { Bromera } 5^{\circ} \\
\text { - En el Tema } 5 \text { se destaca una información muy positiva para } \\
\text { poder entender la diferencia entre la sequía y la escasez de } \\
\text { agua: "sobreexplotación de acuíferos que no tiene nada que } \\
\text { ver con la sequía ni la falta de lluvias" (Gregori \& Viu, 2014, } \\
\text { p. 57). } \\
\text { - En cuanto al cambio climático, en el Tema } 2 \text { (apartado de } \\
\text { "Riesgos naturales climáticos" se explica que "algunas de las } \\
\text { consecuencias que comporta son el deshielo de los glaciares } \\
\text { y de los casquetes polares, el aumento del nivel del mar, más } \\
\text { incidencia de las lluvias y de la sequía en determinadas zonas } \\
\text { del mundo" (Gregori \& Viu, 2014, p. 30). }\end{array}$ & Sí. & Sí. \\
\hline
\end{tabular}


Tabla 6. Continuación

\begin{tabular}{|c|c|c|}
\hline $\begin{array}{l}\text { Bromera } 6^{\circ} \\
\text { - En cuanto al cambio climático se destaca que una de sus } \\
\text { consecuencias será "el aumento de las sequías" (Gregori \& } \\
\text { Viu, 2015, p. 29). }\end{array}$ & $\begin{array}{l}\text { No hay } \\
\text { información. }\end{array}$ & Sí. \\
\hline $\begin{array}{l}\text { Santillana } 5^{\circ} \\
\text { - Respecto al cambio climático una de las consecuencias será: } \\
\text { "se harán más frecuentes los periodos de lluvias muy intensas } \\
\text { o de sequías prolongadas" (Grence, 2015, p. 59). }\end{array}$ & $\begin{array}{l}\text { No hay } \\
\text { información. }\end{array}$ & Sí. \\
\hline $\begin{array}{l}\text { Santillana } 6^{\circ} \\
\text { - En relación con el cambio climático se explica que "sus } \\
\text { efectos son muy variados y pueden provocar periodos } \\
\text { prolongados de sequía" (Grence \& Gregori, 2015, p. 79). }\end{array}$ & $\begin{array}{l}\text { No hay } \\
\text { información. }\end{array}$ & Sí. \\
\hline $\begin{array}{l}\text { SM } 5^{\circ} \\
\text { - Respecto al cambio climático se indica que "el calentamiento } \\
\text { causa sequías, desertización y el cambio en ecosistemas. } \\
\text { Algunos animales pueden extinguirse si no se adaptan" (Parra } \\
\text { et al., 2014, p. 36). } \\
\text { - También se encuentra una actividad que induce a pensar que } \\
\text { el cambio climático es una causa directa de las sequías: } \\
\text { "relaciona las inundaciones y las sequías con el cambio } \\
\text { climático. ¿Cómo afectan a las personas?" (Parra et al., } \\
\text { 2014, p. 45). }\end{array}$ & $\begin{array}{l}\text { No hay } \\
\text { información. }\end{array}$ & Sí. \\
\hline $\begin{array}{l}\text { SM } 6^{\circ} \\
\text { - En cuanto al cambio climático se indica que "las sequías son } \\
\text { de origen natural" (Martin et al., 2015, p. 30). }\end{array}$ & No. & Sí. \\
\hline $\begin{array}{l}\text { Vicens Vives } 5^{\circ} \\
\text { - En relación con el cambio climático se explica que "se ha } \\
\text { producido un aumento de los fenómenos meteorológicos } \\
\text { extremos. En los últimos años ha aumentado el número de } \\
\text { inundaciones, sequías, olas de calor y ciclones tropicales" } \\
\text { (García \& Gatell, 2014, p. 53). }\end{array}$ & $\begin{array}{l}\text { No hay } \\
\text { información. }\end{array}$ & Sí. \\
\hline $\begin{array}{l}\text { Vicens Vives } 6^{\circ} \\
\text { - No hay información sobres los factores que afectan al riesgo } \\
\text { de sequía. }\end{array}$ & $\begin{array}{l}\text { No hay } \\
\text { información. }\end{array}$ & $\begin{array}{l}\text { No hay } \\
\text { información. }\end{array}$ \\
\hline
\end{tabular}

Fuente: elaboración propia

Una de las cuestiones que también se han analizado en los libros de texto son las soluciones que se proponen para mitigar los efectos de la sequía y la adaptación a este fenómeno teniendo en 
cuenta los escenarios futuros de cambio climático. En primer lugar, cabe destacar que la mitad de los manuales analizados no incorporan ningún tipo de solución a este riesgo socio-ambiental (Santillana $5^{\circ}$; SM $5^{\circ}$ y $6^{\circ}$; Vicens Vives $5^{\circ}$ y $6^{\circ}$ ). En segundo lugar, destacan aquellos libros de texto (3 de 10) que insertan información sobre el ahorro de agua (Anaya $5^{\circ}$; Bromera $5^{\circ}$ y $6^{\circ}$; Santillana $6^{\circ}$ ). Algunos de los ejemplos que se exponen para ahorrar recursos hídricos son los que tienen que ver con el cierre de grifos mientras se está usando agua para usos domésticos ( $5^{\circ}$ de Bromera): "hay que tener en cuenta que el agua es un recurso limitado y fundamental para la vida, de manera que tenemos que hacer un uso adecuado, no malgastarla y controlar al máximo los índices de contaminación" (Gregori \& Viu, 2014, p. 61).

$Y$, en tercer lugar, se encuentran soluciones que se plantean desde la explotación de los llamados recursos hídricos convencionales (2 manuales). Sin embargo, cabe indicar que estas propuestas son un tanto controvertidas, obsoletas y poco acordes con el objetivo de sensibilizar a las cohortes más jóvenes sobre el uso eficiente del agua. Para el caso de Anaya (6 $6^{\circ}$ curso) se propone como solución a la sequía el incremento de la oferta de agua mediante los trasvases (Figura 1): "para prevenir la sobreexplotación, se intenta racionalizar el uso y distribución del agua mediante la construcción de canales o trasvases, de la construcción de presas o del tratamiento de aguas residuales con el objetivo de aprovechar mejor este recurso mejor" (Benítez et al., 2015, p. 27). Esta explicación quedaría compensada con la propuesta acertada del aprovechamiento de las aguas regeneradas depuradas que, tras ser tratadas, son incorporadas nuevamente en la red tanto para usos domésticos como agrícolas. Sin embargo, explicar estos recursos (convencionales) y no convencionales (caso de las aguas depuradas) conjuntamente para solucionar este problema socio-ambiental no sería del todo correcto, sino que se debería diferenciar las ventajas y desventajas que puede ofrecer cada uno. Y sobre todo que entiendan la diferencia entre recurso convencional y no convencional. Una propuesta similar sucede con las aguas subterráneas (explotación de acuíferos) como solución a la sequía que según el manual de Bromera de 60, "son depósitos subterráneos naturales de agua. Cuando llueve, parte de la lluvia se filtra debajo de la tierra hasta que se encuentra una capa impermeable y queda retenida; entonces se forma un acuífero. Constituyen reservas de agua para las épocas de sequía, pero en los últimos años han sido sobreexplotados por la abertura masiva de pozos y se están secando" (Gregori \& Viu, 2014, p. 64). 
Figura 1. Fotografías que incorpora el libro de texto de $6^{\circ}$ de Educación Primaria (editorial Anaya) sobre sobre trasvases y aguas regeneradas depuradas

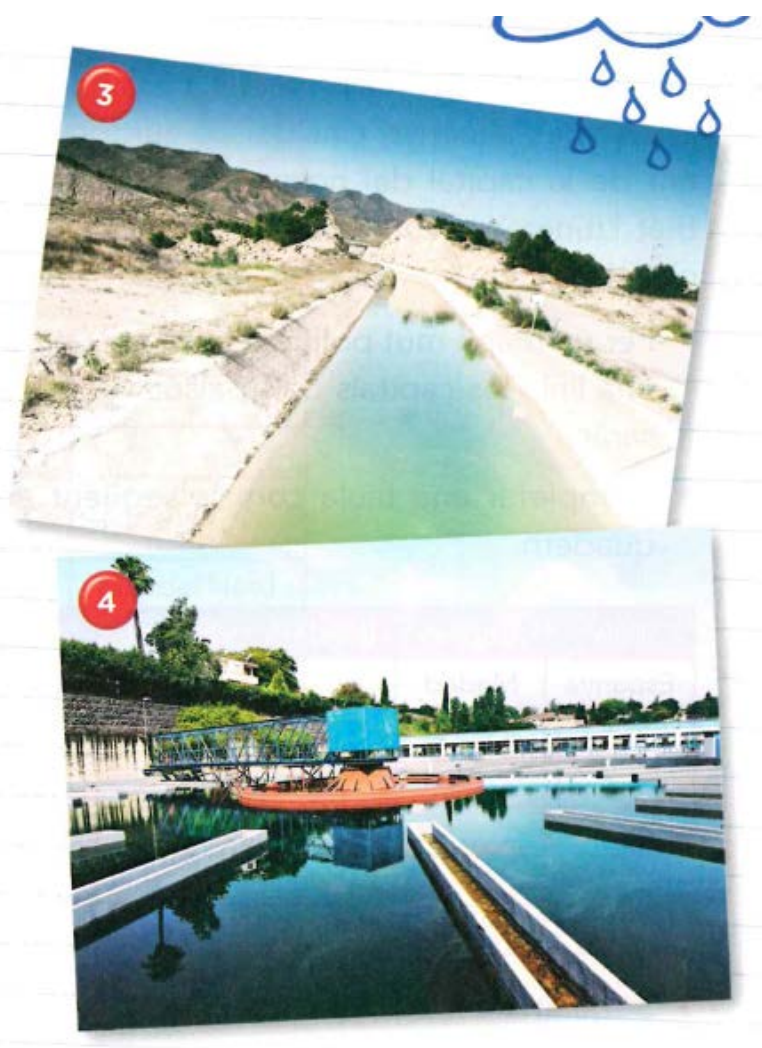

Nota: aunque no se indica, la canalización que se observa en la imagen es el Trasvase Tajo-Segura, una de las transferencias hídricas más controvertidas de Europa.

Fuente: Benítez et al. (2015, p. 27)

Figura 2. Fotografía de un desierto que incorpora el libro de texto de $6^{\circ}$ de Educación Primaria (editorial Santillana)

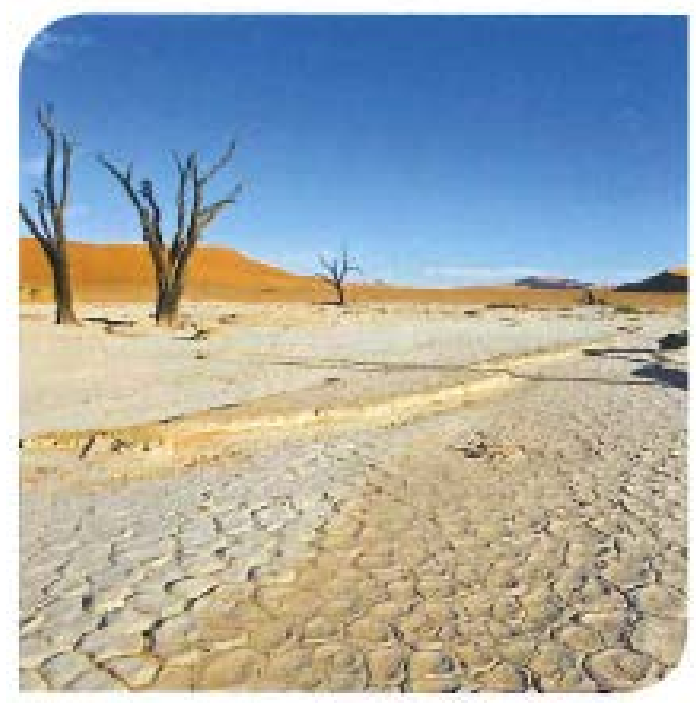

Fuente: Grence \& Gregori (2015, p. 84). 
Finalmente se han analizado las imágenes que se insertan en relación con los contenidos sobre la sequía. De un total de 7 imágenes asociadas a este fenómeno, 4 se caracterizan por insertarse con una funcionalidad meramente estética, caracterizándose la mayoría de estas por un abuso del mensaje catastrofista. Incluso algunas imágenes se refieren a eventos de otras regiones climáticas muy lejanas a la región mediterránea, por ejemplo, las que se vinculan con desiertos (Figura 2) o regiones españolas donde estos paisajes son característicos como pueden ser algunas áreas del sureste peninsular (Almería) (Figura 3).

Figura 3. Fotografía de un área semiárida de Andalucía que incorpora el libro de texto de $5^{\circ}$ de Educación Primaria (editorial Vicens Vives)

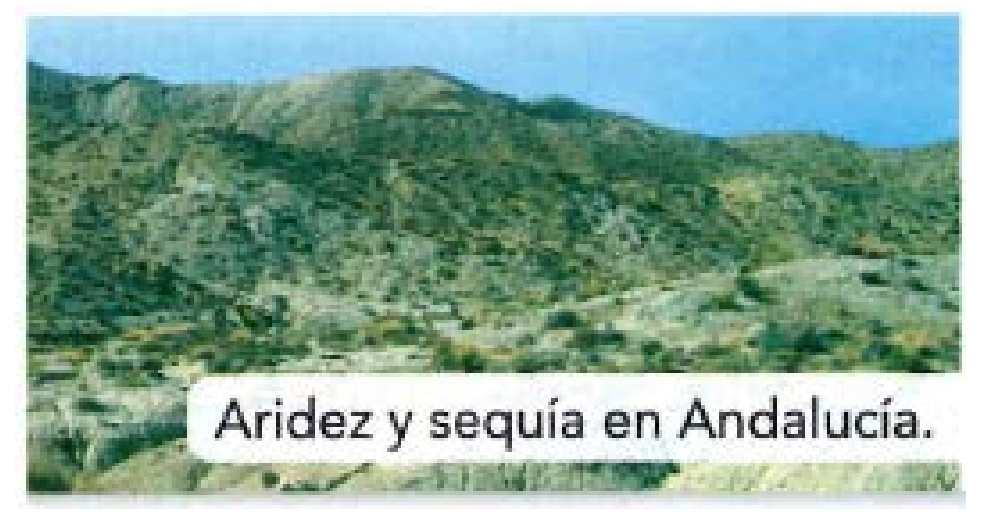

Fuente: García \& Gatell (2014, p. 53)

\section{Discusiones}

La realización de esta investigación ha permitido analizar cómo se trata el riesgo de sequía en los manuales escolares objeto de estudio. En cuanto a las hipótesis iniciales, estas se cumplen ya que esta temática: 1) adquiere una escasa atención y confusa en los libros de texto (hipótesis 1); 2) una de las causas principales de este fenómeno estaría vinculada con el cambio climático (hipótesis 2); y 3) en relación con las imágenes, estas tienen la finalidad de dar una imagen catastrófica y, además, descontextualizada con los contenidos (hipótesis 3).

En cuanto a las definiciones se ha podido comprobar que sólo 2 de 10 manuales escolares hacen una correcta explicación del fenómeno de la sequía. Este dato representa un bajo número debido a la trascendencia socio-ambiental actual que tiene este problema, especialmente en la región mediterránea (área de estudio) y por los efectos futuros del cambio climático. Por otra parte, ningún libro de texto incorpora información sobre las definiciones y diferencias entre sequía pluviométrica e hidrológica. Son conceptos sencillos pero que a la hora de introducir el factor humano (demanda y usos de agua, etc.), cabría matizar y precisar. No obstante, también 
caben destacar algunos aspectos positivos (aunque minoritarios) como es el caso del manual de $6^{\circ}$ (editorial SM) que explica que la sequía también es un fenómeno natural.

También cabría ampliar el ámbito geográfico afectado por el riesgo de sequía. Se ha comprobado que 7 de cada 10 libros de texto asocian la sequía a la región mediterránea, pero cabe indicar que, en España, por su ubicación geográfica, este fenómeno también es característico en otras regiones. Por ejemplo, en el actual siglo XXI cabe recordar que uno de los peores periodos sufridos en la Península Ibérica fue el de 2017-2018 en el que una de las áreas más afectadas fue el norte peninsular. Sin embargo, en el sureste, a pesar de la reducción las precipitaciones, prácticamente no se sufrieron restricciones ni problemas de abastecimiento de agua gracias a la disponibilidad de recursos hídricos no convencionales (caso de la desalinización) (Morote, 2019b).

También cabe destacar diferentes términos que se suelen asociar al de sequía pero que poco tienen que ver con este fenómeno si no se explica o se matiza. Son los casos de los conceptos de sequía estival y estiaje, España seca, aridez, escasez de agua y desertificación. Estos se suelen vincular con el riesgo de sequía, pero sin embargo no se explica la interrelación que tiene el factor vulnerabilidad (ser humano) y cómo este puede incidir en que un territorio sea más vulnerable a este riesgo. Un ejemplo sería diferenciar entre sequía pluviométrica e hidrológica. La mejora de este rigor conceptual no debería ser una limitación en estos libros de texto teniendo en cuenta que se relacionan con el $3^{\text {er }}$ ciclo de Educación Primaria (edad entre los 11-12 años) y cursos previos a la ESO, donde los estudiantes pueden tener un aprendizaje más crítico (Martínez \& Olcina, 2019). En el ámbito educativo, estas argumentaciones y conceptos se conocen como la transposición didáctica, que según Chevallard (1991) se entiende como el paso del saber sabio al saber enseñado ya que el conocimiento sufre transformaciones para enseñarlo en el aula.

Este escaso rigor científico también ha sido demostrado por García et al. (2009) en relación con la explicación de los problemas ambientales en los manuales escolares de Geografía que presentan deficiencias vinculadas con la formación de una ciudadanía comprometida con los conflictos ambientales. Estos autores ponen de manifiesto que existe una reducida referencia a experiencias directas que relacionen los conocimientos aprendidos con la vida cotidiana del alumnado. Ello dificulta la habilidad para establecer relaciones entre los problemas ambientales y la vida cotidiana que puede vincularse con una cierta insensibilidad colectiva hacia la situación ambiental del territorio. En cuanto a las actividades propuestas, García et al. (2009) explican que 
estas se asocian de manera general con el uso de los manuales como materiales cerrados que contienen la información que se debe aprender y, además, no facilitan su empleo como herramienta con el que aprender de manera más creativa y activa. También estos autores argumentan que sería deseable la inclusión de un mayor número de actividades aplicadas y comprensivas, de análisis y de tipo experimental. Por su parte, Martínez y Olcina (2019), respecto a los contenidos sobre Climatología, indican que se debe llevar a cabo una óptima explicación de estos, la selección de imágenes con un valor didáctico significativo (cielo, nubes, fenómenos atmosféricos relevantes, aparatos de recogida y medida de datos meteorológicos, paisajes asociados a los tipos de climas, etc.), y la correcta elaboración de tablas y, especialmente, de mapas y gráficos.

En cuanto las causas de las sequías caben destacar que la mayoría de los manuales (9 de 10) hacen mención a que el cambio climático es la causa principal. Esto debería matizarse ya que, en todo caso, según las previsiones de los informes internacionales sobre cambio climático (IPCC, 2018), estos eventos serán más frecuentes e intensos. Esto mismo, muy acertadamente lo recoge el libro de $5^{\circ}$ (editorial Bromera). En el trabajo de García et al. (2009), respecto a la desertificación, las causas están referidas a las relacionadas con las de tipo socio-económico $(62 \%)$ y biofísicas (38\%). En vinculación con las consecuencias, estos autores señalan que hacen mención a aspectos del medio natural y ponen de manifiesto que una mejor presencia de los efectos y riesgos de tipo humano podría mejorar la concienciación sobre la gravedad de la situación ambiental. También las relaciones existentes entre problemas ambientales son reducidas y casi siempre hacen mención al cambio climático como agente causal de la pérdida de biodiversidad o desertificación. Otros autores (López \& Oller, 2019), para el caso de las representaciones sociales de los/as futuros/as maestros/as de Educación Primaria han identificado, en relación con principales problemas ambientales: el reciclaje, la contaminación y temas vinculados con los recursos hídricos (sequía y calidad del agua). Por tanto, se puede comprobar que la sequía constituye un problema socio-ambiental de notable interés según ponen de manifiesto los/as propios/as maestros/as en formación.

Estas mismas causas (cambio climático), también se han constatado para otros riesgos (caso de las inundaciones). Por ejemplo, en el trabajo llevado a cabo por Morote (2019a) en relación con las representaciones sociales del futuro profesorado de Educación Primaria, el 64,5\% piensa que el cambio climático tiene una incidencia directa en el aumento de estos fenómenos. También para las inundaciones, Morote y Souto (2020), han comprobado que ningún estudiante (futuro/a maestro/a de Educación Primaria) ha sabido definir los factores que integran la 
ecuación del riesgo (riesgo = peligrosidad + vulnerabilidad). Ello denota la escasa formación disciplinar que tiene el futuro profesorado sobre estos contenidos, situación que se agrava teniendo en cuenta que son alumnos/as de último curso y a las puertas de ejercer su labor profesional.

Por este motivo, habría que despertar en el alumnado un espirito crítico y con una mayor problematización, en este caso, de los riesgos naturales, pero en este trabajo se ha podido comprobar que en la mayoría de los manuales consultados no se consigue. No obstante, es muy positiva la explicación que lleva a cabo el libro de texto de $5^{\circ}$ curso (editorial Bromera) cuando se explica que la sobreexplotación de los acuíferos no tiene nada que ver con la sequía. En este sentido, la mayoría de los manuales consultados, lo que dan a entender es que la sequía es provocada, en primer lugar, por el cambio climático, y en segundo lugar, por el ser humano debido al incremento del consumo de agua, despilfarro de este recurso, etc. Sin embargo, tan sólo un libro ( $6^{\circ}$ curso de la editorial SM) indica que este fenómeno tiene un origen natural.

En relación con las posibles soluciones, García et al. (2009) explican que el conocimiento de estas resulta primordial para conseguir la implicación de la sociedad en la construcción de un futuro sostenible. Por su parte, Vilches y Gil (2008) indican que analizar únicamente los problemas incita al pesimismo y facilita la inacción entre los discentes. En la presente investigación se ha comprobado que en la mitad de los manuales no se han facilitado propuestas. Sin embargo, en algunos libros de texto se insertan soluciones muy acertadas que proponen una reflexión y consejos sobre el ahorro y no malgasto del agua. No obstante, también es cierto que en algunos libros las propuestas que se incorporan son un tanto controvertidas si no se explican las ventajas y desventajas y si no se problematizan estas soluciones. Por ejemplo, son las propuestas de la denominada "vieja política hidráulica" en la que se prima el incremento de la oferta de agua para paliar los problemas de escasez. Esto aún es más controvertido cuando una de las soluciones que se ofrecen son los trasvases. Se tratan de propuestas desfasadas y superadas que se podrían debatir en clase, pero, sin embargo, se pierde esta oportunidad. En contraposición a estas soluciones destacan las que se vinculan con la denominada "economía circular", es decir, las que se relacionan con el tratamiento de aguas regeneradas depuradas. Por tanto, estas dos soluciones (trasvases y aguas regeneradas depuradas) podrían ejercer un debate notablemente interesante en el aula. Esta cuestión (los debates en el aula) según han analizado García et al. (2009) son claramente deficientes en todas las editoriales analizadas en su estudio. 
Desde la formación de los/as estudiantes se debería fomentar un espíritu crítico sobre la comprensión de los contenidos de los manuales y que tengan un conocimiento más real sobre la sequía. Esto mismo ya ha sido explicado por Arrebola y Martínez (2017) para el caso de la tipología de actividades en los libros de texto (Educación Primaria) en vinculación con el cambio climático. Además, cabe poner de manifiesto que se debería favorecer desde la propia formación del profesorado (desde la universidad), una explicación sencilla de los principales elementos de este fenómeno apoyándose con datos e información facilitados por trabajos científicos, al igual que el análisis crítico de noticias de prensa o incluso la información proporcionada en los manuales escolares. Para el caso español, esto mismo ya fue argumentado por Serantes (2015) quien manifestó que era necesaria la incorporación de actividades en los libros de texto de Secundaria, relacionadas con la resolución de problemas sobre el cambio climático y de carácter local.

Respecto a las imágenes se ha comprobado que estas se incorporan con el objetivo de dar una sensación de catastrofismo. Además, en ocasiones son fotografías de otros territorios y descontextualizadas que poco tienen que ver con la sequía. Son, por tanto, imágenes que pueden incitar a la confusión y manipulación, en este caso, a los/as alumnos/as y concretamente porque lo que se intenta es incorporar imágenes estéticas (Sáiz, 2011). Por ejemplo, para el caso de los libros de texto de Ciencias Sociales (Educación Primaria), Morote y Olcina (2020) han comprobado que en un manual escolar se inserta una imagen referida al Monzón pero que, sin embargo, poco o nada tiene que ver con el cambio climático. También, Morote (2020) ha realizado un análisis de las imágenes que se vinculan con los contenidos de Climatología y ha llegado a la conclusión de que estas generalmente se caracterizan por ser de apoyo a los contenidos y, en algunas editoriales, especialmente por ser meramente estéticas. Por su parte, Bel, Colomer y Valls (2019), a partir del análisis de manuales escolares $\left(5^{\circ}\right.$ y $6^{\circ}$ de Educación Primaria) de Conocimiento del Medio (LOE, 2006-2013) y Ciencias Sociales (LOMCE) adscritos a la Comunidad Valenciana, han comprobado que se mantiene un uso decorativo de las imágenes.

Esta imagen de catastrofismo puede estar notablemente influenciada por los medios de comunicación y más concretamente cuando se tratan contenidos como la sequía (notablemente interrelacionada con el cambio climático). En este sentido, Martín-Vide (2009) indica la importancia que tiene tratar esta temática debido a la manipulación y falsedad que se hace desde los medios de comunicación. Por su parte, Kays (2018) argumenta el conflicto que supone la información no veraz desde estos medios respecto al cambio climático debido a la 
falsedad y manipulación, mientras que Allen, McAleer y McHardy-Reid (2018) dan importancia a la influencia que tienen sobre la sociedad actual estos medios debido a las denominadas fake news. Esta influencia también queda reflejada en los manuales según indican Morote y Olcina (2020) y García et al. (2009). Estos últimos han analizado que predominan las referencias externas al manual vinculadas principalmente con direcciones de Internet, asiduamente como fuente de procedencia de la información, pero de manera general como medio para aumentar conocimientos o fomentar determinadas actividades.

Finalmente cabe indicar que una de las cuestiones clave que los libros de texto deben contemplar es la componente "vulnerabilidad". Al respecto, según indica Morote (2019b) para el análisis del riesgo de sequía cabe tener en cuenta dos aspectos fundamentales: la variable peligrosidad (episodio caracterizado por la reducción de precipitaciones por debajo de lo considerado "normal") y el estado de la vulnerabilidad de un territorio para hacer frente a este peligro. En el ámbito anglosajón (Geographical Association) desde hace varias décadas, en la Educación Primaria se está trabajando sobre estas cuestiones y más concretamente sobre el cambio climático (Spear, 2018). Se tratan de propuestas educativas en las que cobra protagonismo el factor vulnerabilidad. En este sentido, según pone de manifiesto un informe publicado por la Agencia Medioambiental Europea, existe la urgencia de dar una mayor importancia a este factor porque se trata de un elemento clave para la adaptación al cambio climático y el previsible incremento de episodios atmosféricos extremos (European Environment Agency, EEA, 2017).

\section{Conclusiones}

Una de las principales conclusiones extraídas de este trabajo es que el riesgo de sequía, a pesar de que sí que se trata en los libros de texto, debería mejorarse su explicación e interrelación de los factores humanos y climáticos que intervienen. Por tanto, se ha comprobado que la explicación de este fenómeno (tan característico del clima mediterráneo) se trata de una explicación vulgar y donde el ser humano pasa desapercibido a la hora de analizar el riesgo. Se ha comprobado que el cambio climático es una de las principales causas, pero esto debería matizarse ya que lo que indican los informes internacionales es que las sequías serán en el futuro más intensas y frecuentes. Por ello, de no mejorarse esta información en los manuales escolares, sería necesario incrementar y mejorar la formación del profesorado sobre estas temáticas. No cabe olvidar que tanto en los libros de texto como las propias representaciones sociales de los docentes abundan las informaciones influidas por los medios de comunicación que tienen que 
ver con el cambio climático (Morote \& Olcina, 2020). Además, recientemente estos contenidos han obtenido un respaldo en el ámbito educativo gracias a la aprobación (mayo de 2020) del Proyecto de ley de Cambio Climático en que se recoge un apartado específico sobre "Educación y capacitación frente al cambio climático". Por tanto, se disponen de las herramientas y normativas necesarias para mejorar la formación escolar. Sólo falta compromiso y que estas políticas se vean implementadas en la realidad de las aulas y en la formación del profesorado.

Cabe indicar que no todos los temas pueden tratarse con una máxima extensión. Por tanto, queda a juicio de las editoriales elegir con qué profundidad y amplitud tratar los contenidos que se recogen en el currículo. Y en relación con el profesorado es muy importante que conozca las fortalezas y debilidades de los libros de texto que se utilizan para ampliar y/o suplir las carencias (Arrebola \& Martínez, 2017). Casi exclusivamente, la realidad docente en las aulas depende de las habilidades del profesorado para transmitir estos conocimientos, elemento que no ha sido analizado en esta investigación. Esta cuestión, la transmisión real de los contenidos de los libros de texto constituye un reto futuro de investigación. Otro de los retos debe pasar por el análisis de las actividades (grado de complejidad y de problematización) que se proponen para explicar las sequías en el aula y, asimismo, comparar con otras experiencias internacionales. Este trabajo ha pretendido ser una primera aproximación al tratamiento del riesgo de sequía en los libros de texto de Educación Primaria. Por tanto, queda abierta a futuros trabajos para avanzar en la transmisión a la sociedad sobre esta temática, generando métodos de análisis de los contenidos de los manuales escolares no universitarios de Ciencias Sociales y/o Geografía.

Agradecimientos: El autor quiere expresar un cordial sentido de gratitud al profesor Xosé Manual Souto por las sugerencias y consejos realizados para la elaboración de este trabajo. Esta investigación se inserta en el proyecto "Las representaciones sociales de los contenidos escolares en el desarrollo de las competencias docentes" (PGC2018-094491-B-C32) financiado por el Ministerio de Ciencia, Innovación y Universidades y cofinanciado con fondos FEDER de la UE.

Declaración responsable: El/la autor/a declara que no existe ningún conflicto de interés con relación a la publicación de este artículo. 


\section{Bibliografía}

Allen, D.E., McAleer, M., \& McHardy-Reid, D. (2018). Fake news and indifference to scientific fact: President Trump's confused tweets on global warming, climate change and weather. Scientometrics, 117(1), 625-629.

Arrebola, J.C., \& Martínez, R. (2017). El cambio climático en los libros de texto españoles de Educación Primaria: Un análisis de las actividades. In A. Cristina, E. Sande \& M. Helena (Eds.), VIII Congreso Ibérico de Didáctica da Geografía (pp. 581-560). Lisboa (Portugal): Associação de Professores de Geografia.

Bel, J.C., \& Colomer, J.C. (2018). Teoría y metodología de investigación sobre libros de texto: análisis didáctico de las actividades, las imágenes y los recursos digitales en la enseñanza de las Ciencias Sociales. Revista Brasileira de Educação, (23), 1-23. https://doi.org/10.1590/s1413$\underline{24782018230082}$

Bel, J.C., Colomer, J.C., \& Valls, R. (2019). Alfabetización visual y desarrollo del pensamiento histórico: Actividades con imágenes en manuales escolares. Educación XX1, 22(1), 353374. https://doi.org/10.5944/educXX1.20008

Benítez, J.K., Cano, J.A., Fernández, E., \& Marchena, C. (2014). Ciencias Sociales 5. Madrid: Grupo Anaya.

Benítez, K., Cano, J.A., Fernández, E., \& Marchena, C. (2015). Ciencias Sociales, 6: Primaria. Madrid: Grupo Anaya.

Calvo, F. (2001). Sociedades y Territorios en Riesgo. Barcelona: Ediciones Serbal.

Chevallard, Y. (1991). La Transposition Didactique du Savoir Savant au Savoir Enseigné. Grenoble, France: La Pensée Sauvage éditions.

Chitsaz, N., \& Hosseini, S. (2017). Introduction of new datasets of droughts índices based on multivariate methods in semi-arid regions. Hydrology Research, 49(1), 266280. https://doi.org/10.2166/nh.2017.254

Committee of Professional Agricultural Organisations-General Confederation of Agricultural Cooperatives (COPA-COGECA) (2003). Bewertung der Auswirkungen der Hitzewelle und Dürre des Sommers 2003 für Land- und Forstwirtschaft. Retrieved from https://www.deutschlandfunknova.de/beitrag/sommer-auswirkungen-der-hitzewelle 
Cuello, A., \& García, F. (2019). ¿Ayudan los libros de textos a comprender la real fluvial de la ciudad? Revista de Humanidades, (37), 209-234.

European Environment Agency (EEA) (2017). Climate change, impacts and vulnerability in Europe 2016. An indicator-based report. Luxemburgo. Retrieved from https://www.eea.europa.eu/publications/climate-change-impacts-and-vulnerability-2016

Ferrer, M., Bonafeu, D., Costa, M., Estrada, M., \& Roger, E. (2009). Ciencies de la Terra i del medi ambient. Barcelona: Castellnou.

García, M., \& Gatell, C. (2014). Sociales, 5 Educación Primaria. Vicens Vives.

García, M., Gatell, C., \& Batet, M. (2015). Sociales 6․ Vicens Vives.

García, J., Pardo, P., \& Rebollo, L.F. (2009). La desertificación y otros problemas ambientales en los libros de texto de geografía de educación secundaria en España. In F. Pillet, M.C. Cañizares, A. Ruiz (Coord.), Geografía, territorio y paisaje. El estado de la cuestión: actas del XXI Congreso de Geógrafos Españoles (pp. 1757-1772). Ciudad Real: Asociación de Geógrafos Españoles.

Generalitat Valenciana (2020). Decreto 108/2014, de 4 de julio, del Consell, por el que se establece el currículo y desarrolla la ordenación general de la educación primaria en la Comunitat Valenciana. Retrieved from

http://www.dogv.gva.es/datos/2014/07/07/pdf/2014_6347.pdf

Gregori, J., \& Viu, M. (2014). Crónica 5. Ciencias Sociales. Alzira: Ediciones Bromera.

Gregori, J., \& Viu, M. (2015). Ciencias sociales 6․ Alzira: Ediciones Bromera.

Grence, T. (2015). Ciencias Sociales. $5^{\circ}$ de Primaria. Santillana Voramar.

Grence, T., \& Gregori, I. (2015). Ciencias Sociales 6. Picanya: Ediciones Voramar, Santillana Educación.

Gobierno de España (2020). Real Decreto 126/2014, de 28 de febrero, por el que se establece el currículo básico de la Educación Primaria. Boletín Oficial del Estado. Retrieved from https://www.boe.es/buscar/pdf/2014/BOE-A-2014-2222-consolidado.pdf

Intergovernmental Panel on Climate Change (IPCC) (2018). Special Report Global warming of $1.5^{\circ} \mathrm{C}$. Retrieved from

https://www.ipcc.ch/report/sr15/ 
Kažys, J. (2018). Climate change information on internet by different Baltic Sea Region languages: Risks of disinformation \& misinterpretation. Journal of Security and Sustainability Issues, 7(4), 685-695.

La Calle, A. (2007). Sequía y adaptación de la Directiva marco del agua. La Sequía en España. Directrices para Minimizar su Impacto. Madrid: Ministerio de Medio Ambiente.

López, J.A., \& Oller, M. (2019). Los problemas medioambientales en la formación del profesorado de educación primaria. REIDICS: Revista de Investigación en Didáctica de las Ciencias Sociales, (4), 93-109.

Martín, J. (2009). Diez verdades y diez mentiras en relación al cambio climático. Enseñanza de las Ciencias de la Tierra, 17(2), 120-127.

Martin, S., Parra, E., De la Mata, A. Hidalgo, J.M., \& Moratalla, V. (2015). Ciencias Sociales 6. SM.

Martínez, R., \& López, J.A. (2016). La enseñanza de la climatología en los manuales escolares de Ciencias Sociales en Educación Primaria. In R. Sebastiá \& E. Tonda (Eds.), La investigación e innovación en la enseñanza de la Geografía (pp. 245-258). Alicante: Servicio de Publicaciones de la Universidad de Alicante.

Martínez, L.C., \& Olcina, J. (2019). La enseñanza escolar del tiempo atmosférico y del clima en España: currículo educativo y propuestas didácticas. Anales de Geografía de la Universidad Complutense, 39(1), 125-148.

Morales, A., Olcina, J., \& Rico, A.M. (2000). Diferentes percepciones de la sequía en España: adaptación, catastrofismo e intentos de corrección. Investigaciones Geográficas, (23), 5-46.

Morote, A.F. (2019a). Percepción de los futuros maestros de Primaria sobre el riesgo de inundación. La Geografía como herramienta para lograr una sociedad más resiliente al cambio climático. Papeles de Geografía, (65), 67-88. http://dx.doi.org/10.6018/geografia.366341

Morote, A.F. (2019b). Galicia ¿territorio adaptado a la sequía? Cuadernos Geográficos, 58(2), 6-33. http://dx.doi.org/10.30827/cuadgeo.v58i2.7627

Morote, A.F. (2020). ¿Cómo se trata el tiempo y clima en la Educación Primaria? Una exploración a partir de los recursos y actividades de los manuales escolares de Ciencias Sociales. Espacio, Tiempo y Forma, Serie VI Geografía, (13), 119-144. 
Morote, A.F., \& Olcina, J. (2020). El estudio del cambio climático en la Educación Primaria: una exploración a partir de los manuales escolares de Ciencias Sociales de la Comunidad Valenciana. Cuadernos Geográficos, 158177. http://dx.doi.org/10.30827/cuadgeo.v59i3.11792

Morote, A.F., \& Souto X. M. (2020). Educar para convivir con el riesgo de inundación. Estudios Geográficos, 81(288), 1-14. https://doi.org/10.3989/estgeogr.202051.031

Olcina, J. (2001). Causas de las sequías en España. Aspectos climáticos y geográficos de un fenómeno natural. In A. Gil \& A. Morales (Eds.), Causas y consecuencias de las sequías en España (pp. 49-109). Alicante: Instituto Universitario de Geografía de la Universidad de Alicante y Caja de Ahorros del Mediterráneo.

Olcina, J. (2017). La enseñanza del tiempo atmosférico y del clima en los niveles educativos no universitarios. Propuestas didácticas. In R. Sebastiá \& E. M.Tonda (Eds.), Enseñanza y aprendizaje de la Geografía para el siglo XXI (pp. 119-148). Alicante: Servicio de Publicaciones de la Universidad de Alicante.

Olcina, J. (2018). Verdades y mentiras sobre el riesgo de inundaciones en el litoral mediterráneo: balance de medio siglo. In Jornada sobre fenómenos meteorológicos extremos en el mediterráneo. 11 de diciembre de 2018. Valencia: AEMET.

Olcina, J. (2020). Clima, cambio climático y riesgos climáticos en el litoral mediterráneo. Oportunidades para la geografía. Documents d'Anàlisi Geogràfica, 66(1), 159182. https://doi.org/10.5565/rev/dag.629

Pagès, J. (2008). Los libros de texto de ciencias sociales, geografía e historia y el desarrollo de las competencias ciudadanas. Textos escolares de historia y ciencias sociales, Seminario Internacional (pp. 24-56). Santiago de Chile: Ministerio de Educación de Chile.

Paneque, P., La fuente, R., \& Vargas, J. (2018). Public Attitudes toward Water Management Measures and Droughts: A Study in Southern Spain. Water, (10), 369. https://doi.org/10.3390/w10040369

Parra, E., Martín, S., Navarro, A., \& López, S. (2014). Ciencias Sociales. Comunitat Valenciana. $5^{\circ}$ Primaria. SM.

Prats, J. (2012). Criterios para la elección del libro de texto de historia. Histodidáctica, (70), 7-13. Ramos, J.M., \& Calonge, G. (2014). Renovación de la didáctica de la Geografía física en segundo de bachillerato: La climatología como ejemplo. Didáctica Geográfica, (15), 129-151. 
Real Academia Española de la Lengua (2020). Diccionario de la Lengua Española. Retrieved from https://www.rae.es/

Sáiz, J. (2011). Actividades de libros de texto de Historia, competencias básicas y destrezas cognitivas, una difícil relación: análisis de manuales de $1^{\circ}$ y $2^{\circ}$ de ESO. Didáctica de las Ciencias Experimentales y Sociales, (25), 37-64.

Sánchez-Fuster, M.C. (2017). Evaluación de los recursos didácticos utilizados en Ciencias Sociales, Geografía e Historia en Educación Primaria (Doctoral dissertation, Universidad de Murcia, Spain). Retrieved from https://digitum.um.es/digitum/handle/10201/54567

Serantes, A. (2015). Como abordan o Cambio Climático os libros de texto da Ensinanza Secundaria Obligatoria na España. AmbientalMENTEsustentable, (20), 249262. https://doi.org/10.17979/ams.2015.2.20.1609.1603

Silverio, Á. (1998). Experiencias y conclusiones después de una larga sequía en el área metropolitana de Bilbao. In E. Cabrera \& J. García-Serra (Eds.), Gestión de Sequías en Abastecimientos Urbanos (pp. 475-520). Vila-Real: Universidad Politécnica de Valencia.

Souto, X. M. (2002). Los manuales escolares y su influencia en la instrucción escolar. Biblio 3W, Revista Bibliográfica de Geografía y Ciencias Sociales, VII(414). Retrieved from http://www.ub.es/geocrit/b3w-414.htm

Souto, X.M. (2007). Educación Geográfica y Ciudadanía. Didáctica Geográfica, (9), 11-32.

Spear, P. (2018). Get in the pictures about climate change. Primary Geography, (96), 26-27.

Tonda, E., \& Sebastiá. R. (2003). Las dificultades en el aprendizaje de los conceptos de tiempo atmosférico y clima: la elaboración e interpretación de climogramas. Revista de Educación de la Universidad de Granada, (16), 47-69.

United Nations (2015). Sustainable Development Goals. UNDP, Sustainable Development Agenda. Retrieved from https://www.undp.org/content/undp/es/home/sustainabledevelopment-goals/resources.html

Valls, R. (2007). Historiografía Escolar Española: Siglos XIX-XXI. Madrid: UNED.

Vilches, A., \& Gil, D. (2008). La construcción de un futuro sostenible en un planeta en riesgo. Alambique, Didáctica de las Ciencias Experimentales, (55), 9-19.

White, G.F. (1974). Natural hazards, local, national, global. Oxford University Press.

Wilhite, D. A. (2000). Drought: A Global Assessment. New York: Routledge. 